\title{
FEDERALISMO FISCAL NO BRASIL: DA TEORIA FEDERALISTA À CRISE ECONÔMICA
}

\section{FEDERALISM IN BRAZIL: FROM THE FEDERALIST THEORY TO THE ECONOMIC CRISIS}

\section{EMERSON ADEMIR BORGES DE OLIVEIRA}

Pós-Doutor pela Universidade de Coimbra. Doutor e Mestre em Direito do Estado pela Universidade de São Paulo. Professor Assistente Doutor nos cursos de Graduação, Especialização, Mestrado e Doutorado em Direito da Universidade de Marília. Coordenador-Adjunto do Programa de Mestrado e Doutorado em Direito da Universidade de Marília. Advogado e parecerista. emerson@unimar.br.

\section{MARISA ROSSIGNOLI}

Mestre em Economia pela Pontifícia Universidade Católica de São Paulo - PUC-SP e Doutora em Educação (Política e Gestão) pela Universidade Metodista de Piracicaba - UNIMEP. Professora Assistente Doutora do Programa de Mestrado e Doutorado em Direito da Universidade de Marília - UNIMAR. Delegada Municipal do Conselho Regional de Economia - CORECON -SP para o município de Marília. mrossignoli@unimar.br.

\section{RESUMO}

Este trabalho objetiva discutir importantes momentos do federalismo brasileiro e apontar alguns elementos para o debate sobre as questões federativas em momentos de crise e queda da arrecadação conforme o vivenciado pelo Brasil. Primeiramente, prima por explorar a teoria federalista, seguida de um aprofundamento quanto ao federalismo fiscal brasileiro. Oportunamente, passa a estabelecer críticas ao modelo de federalismo fiscal centrífugo, mormente no contexto atual de crise econômica. Reconhece no sistema fiscal brasileiro um significativo impeditivo a um federalismo 
de equilíbrio, com a necessidade de busca de recursos pelos entes federativos em relação à União, situação geradora de distúrbios democráticos e problemas institucionais. O método é o dedutivo e a pesquisa bibliográfica.

PALAVRAS-CHAVE: Crise econômica; Distribuição vertical de recursos; Federalismo Fiscal.

\section{ABSTRACT}

This paper aims to discuss important moments of Brazilian federalism and to point out some elements for the debate on federative issues in times of crisis and fall in revenue as experienced by Brazil. First of all, it is necessary to explore federalist theory, followed by a deepening of Brazilian fiscal federalism. It is expanded by considerations of revenue breakdowns, revenue unbundling, contribution creation, fiscal warfare, corrupting effects of the federal tax system, and taxpayer legal uncertainty. It recognizes in the Brazilian tax system a significant impediment to a balanced federalism, with the need to seek resources from the federative entities in relation to the Union, a situation that generates democratic disturbances and institutional problems. Opportunely, it begins to criticize the centrifugal fiscal federalism model, especially in the current context of economic crisis. The method is deductive and bibliographic research.

KEYWORDS: Economic crisis; Vertical distribution of resources; Fiscal Federalism.

\section{INTRODUÇÃO}

O federalismo decorre de criação eminentemente norte-americana, a influenciar o processo de confecção da Constituição de 1787. James Madison, Alexander Hamilton e John Jay, à época nos idos da discussão da criação de uma nova Constituição aos Estados Unidos e da assunção de uma nova forma de Estado, que pudesse permitir uma maior proteção a todos, produziram uma coletânea de 85 
(oitenta e cinco) artigos, sob o codinome Publius, publicados principalmente no Independent Journal. Os três apresentavam ideias que diziam respeito à toda forma de organização do Estado Norte-Americano, baseados num princípio chamado de federalismo. Daí porque serem chamados de os federalistas.

De acordo com esse princípio, um país deveria ser formado por um ente federado forte, resultado da união de todos os demais entes, aquilo que comumente chamamos de "Estados", ou melhor, Estados-Membros. Dessa união nasceria, como se pode concluir, a União. Ao mesmo tempo, manter-se-ia certa autonomia aos Estados-Membros, que teriam organização e competências próprias, com divisão de tarefas administrativas e legislativas. Mas tais Estados-Membros não seriam soberanos, e sim meramente autônomos. Isso significa que tais Estados-Membros não possuiriam a mesma força política de um país, sendo, na realidade, parte dele, embora preservando uma parcial "independência".

O Federalismo é, assim, uma forma de Estado em que existe um ente forte, fruto da junção, da aliança, de todos os entes federados autônomos, mas permanece a existência desses entes federados (União, Estados, Distrito Federal e Municípios), para cuidar de assuntos que a própria Constituição Federal Ihes atribui. Quando o assunto for comum, no entanto, como a defesa nacional, a representação do país no exterior, emissão de moeda etc, esse assunto não será tratado pelos EstadosMembros, mas sim pela soma deles, pela união.

A partir de 1891, o Brasil incorpora, pelas mãos de Rui Barbosa, a ideia norteamericana, mas o faz de forma completamente diversa dos Estados Unidos.

Nos Estados Unidos, antes da criação do Estado Federado, existiam treze Estados soberanos que se uniam com base em um tratado internacional que resolveram abdicar desse modelo para se unificar pelo sistema federalista. Assim, abriram mão de sua soberania em prol da soberania da união, preservando para si uma autonomia. Como quem abre mão de suas competências em prol do todo tentará ao máximo preservar para si aquilo que é importante, os Estados Norte-Americanos deram à União apenas o essencial para que ela pudesse cuidar do todo, mantendose fortes em atribuições. É por isso que nos Estados Unidos são os Estados que legislam sobre as matérias mais importantes, como direito civil e direito penal. É por isso que a repartição de receitas privilegia os Estados e não a União. 
Enquanto isso, o Brasil Imperial apresentava-se como um Estado Unitário, altamente centralizador, com todas as decisões nas mãos do Imperador. O preâmbulo da Constituição de 1824 proclamava Dom Pedro I, enquanto aquele que detinha a "graça de Deus", o "Imperador Constitucional", o que possuía "unânime aclamação dos povos" e, ainda, o "Defensor Perpétuo do Brasil". O artigo 99 da mesma Constituição classificava o Imperador do Brasil como pessoa inviolável, irresponsável e sagrada. Possuía até mesmo um Poder chamado de Moderador, criado na Europa por Benjamin Constant em 1.815, que the permitia interferir no Legislativo e no Executivo, colocando-se esse quarto poder acima de todos os outros.

Fora esse Brasil extremamente centralizador que, após a Proclamação da República, resolveu se converter em um Estado Federado, como os Estados Unidos. Percebam, no entanto, que o movimento é inverso. Foi a União que teve que abrir parte de suas competências e poderes para repassá-los aos Estados-Membros. Como é óbvio, quando ela o faz, não o faz em relação às competências mais importantes. Por isso é que no Brasil, para usar o mesmo exemplo anteriormente dado, quem legisla sobre direito civil e direito penal é a União, e não os Estados. É por isso que, como veremos, o movimento fiscal gira muito mais em torno da União.

No Brasil, como se vê, o federalismo formou-se do centro (União centralizadora) para os cantos, abdicando o ente centralizador de suas competências. Em razão dessa fuga do centro, é conhecido como federalismo centrífugo. Nos Estados Unidos, o federalismo formou-se a partir de Estados que eram soberanos e abdicaram dessa soberania para se unirem e formarem um ente maior. Em vista desse caminhar para o centro, seu federalismo é conhecido como centrípeto.

Como adiantado, o grande pressuposto deste artigo é a desigual distribuição de competências legislativas, administrativas e receitas no federalismo brasileiro, o que, em certa parte, permite questionar a própria existência de um verdadeiro federalismo.

Além da formação federalista invertida, cumpre frisar que a partir dos anos 30 , com o governo de Getúlio Vargas, inicia-se um movimento ainda maior de concentração de rendas nas mãos da União, com a clara intenção de tornar EstadosMembros dependentes das vontades do governo centralizador. Essa mesma vertente acentuou-se com a reforma tributária de 1966, ocasião em que, no intuito de publicizar 
certa compensação, criou-se um sistema de transferências, envolvendo, por exemplo, os Fundos de Participação de Municípios e Estados.

Somente em 1988, no intuito de democratizar o país, inicia-se, a vagarosos passos, uma tentativa de inverter a lógica centralizadora. Embora muitos esforços possam ser destacados, como a participação maior de Estados e Municípios na partilha de receitas tributárias, os estudos constitucionais demonstram que a Constituição ainda manteve a União enquanto o ente forte do federalismo, pouco deixando a Estados, Distrito Federal e Municípios, tanto nos aspectos legislativos quanto fiscais.

Assim, por exemplo, o artigo 22, que trata da competência legislativa privativa da União, traz um rol com nada menos do que 29 (vinte e nove) incisos materiais, extraordinário em face dos limitadíssimos artigos 25 e 30 da Constituição.

Mais importante ao nosso objetivo, os artigos 153 a 162 demonstram a forte inclinação em prol de arrecadações substanciais em prol da União, com repasses irrisórios a Estados, Distrito Federal e Municípios. De fato, não há federalismo real, baseado na lógica de igualdade entre os entes federados, em um sistema que dependa em grande parte de repasses voluntários.

Não bastasse, fato é que a União ainda buscou recuperar algumas receitas irrisórias que foram transferidas aos demais entes por meio de criação de contribuições especiais. Ainda, com o mesmo intuito, nasce a Desvinculação de Receitas da União - DRU.

A discussão acerca do falso federalismo - ao menos o falso federalismo fiscal - no Brasil acentua-se ainda mais nos momentos de crise econômica, como na atualidade. Desde o final de 2016, cerca de 150 (cento e cinquenta) Municípios e 3 (três) Estados no Brasil decretaram estado de calamidade financeira, um misto que decorre de má gestão política, mormente na transição entre governos locais, e crise econômica brasileira.

A já alentada situação precária que torna os entes federados tão dependentes das transferências voluntárias e das conhecidas emendas lobistas legislativas tornase ainda mais alarmante diante da atual crise econômica, falseando ainda mais o nosso conceito de federalismo fiscal. Não é absurdo até mesmo ressaltar que este 
péssimo sistema federalista tornou-se um dos maiores aliados da corrupção institucionalizada.

É fato que o federalismo brasileiro precisa ser repensado em todos os seus aspectos, alternando-se o modo de visão centrífugo para um modelo realmente cooperativo e autônomo, em que os entes se ajudam - todos entre si -, embora todos possuam receitas suficientes para fazer frente às suas necessidades.

São estes aspectos que pretendemos discutir.

\section{UM APROFUNDAMENTO DA TEORIA FEDERALISTA E O FEDERALISMO BRASILEIRO}

O Estado brasileiro é formado pela união, de marca indissolúvel, de todos os entes federados admitidos: União, Estados, Distrito Federal e Municípios, não num aspecto de mera soma, mas de intrincamento e interligação, que, por incansáveis vezes, divide e reúne os entes mencionados nas raias das competências atribuídas pela Constituição.

Mesmo que o caput do artigo $1^{\circ}$ não traga a União como ente federado necessário para que a união forme a República Federativa do Brasil, este é um pressuposto necessário e lógico, eis que a União - em maiúsculo - não representa exclusivamente esta união imprescindível para a formação da República Federal.

Esta, aliás, a lição de Tavares (2013, p.840):

O vocábulo "União", no Direito Constitucional pátrio, designa exatamente uma das entidades federativas componentes da estrutura organizacional brasileira, ao lado dos Estados, Distrito Federal e Municípios. Desde logo, contudo, é preciso alertar para o sentido dúbio do termo. Poder-se-ia imaginar que a União nada mais é do que uma conjunção de Estados, Distrito Federal e Municípios. Ou seja, União no sentido da associação dos referidos entes federativos. Corroboraria esse entendimento a leitura isolada e literal do disposto no art. $1^{\circ}$ (...) Contudo, no art. 18, a Constituição esclarece, peremptoriamente, que a República Federativa do Brasil compreende 'a União, os Estados, o Distrito Federal e os Municípios, todos autônomos'. Portanto, a União não se confunde com o Brasil, sendo apenas um dos entes federativos que compõem o Estado federal brasileiro. 
Esta União - diferentemente da união do art. $1^{\circ}$ - nada mais é do que o ente federativo central, pessoa jurídica de Direito Público interno, detentora de bens e competências que dizem respeito a questões tratadas pela Constituição como atinentes ao governo central brasileiro. Difere da República Federativa do Brasil, embora dela faça parte, em conjunto com Estados, Distrito Federal e Municípios. E é essa República Federativa que representa nosso Estado no plano internacional, isto é, o conjunto de todos os entes federativos, e não apenas a União, embora o conceito possa, como vimos, gerar ambiguidades, pois, na prática, é a União que representa a República no plano internacional, a teor do artigo 21, I a IV, CF. Nesse contexto, a propósito, a União exerce uma competência delegada pela República Federativa do Brasil por sua própria Constituição.

A União, no Brasil, é ente notoriamente forte, o que se denota, no mais das vezes, por suas próprias competências tributárias e, por assim dizer, possuir a chave do cofre para primeiramente receber e, após, repartir uma parte de suas receitas com os demais entes (art. 159), o que será oportunamente debatido neste trabalho. Ademais, muitas competências legislativas de extremo relevo são de exclusividade de tal ente (art. 22), como direito civil, eleitoral, penal, dentre outros.

$\mathrm{Na}$ outra ponta, aos Municípios, em geral, pouco sobra, tratando, quase sempre, de assuntos de interesse local (art. 30), capitaneando recursos escassos que acabam conduzindo para a necessidade de repasses voluntários e imensa criatividade de sua fiscalização tributária para criar teses de enquadramento nos impostos de sua competência.

Logo, a despeito de se afirmar constantemente que os entes federados não se encontram hierarquizados, é sensível a vantagem que a União possui sobre os demais, bem como a que Estados possuem sobre Municípios. A ideia simplista de autonomia dos entes federados, bem como da existência de competências próprias, não supre a necessidade de se buscar um equilíbrio real entre os entes, de modo que, principalmente, os recursos financeiros e as competências legislativas não coloquem a União em grau de importância maior do que os Estados, Distrito Federal e Municípios. Como ressalta Araújo (1995, p.43), "impõe-se, ao lado da repartição constitucional de competência, anotar a necessidade de que os Estados ou mesmo a União tenham rendas próprias todas consagradas na Constituição Federal”. E não 
apenas! Mas que tais rendas sejam suficientes para lidar com suas necessidades locais, sem olvidar a questão tão alentada das competências legislativas.

No Brasil, o equilíbrio entre os entes federativos, geralmente representado por sua pretensa autonomia e repartição de competências, é apenas teórico. E sempre fora dessa forma. A razão decorre do federalismo pátrio.

Federação decorre de foederis e traduz a ideia de aliança. Advém da ideia de Estados se associando para a formação de um novo Estado, resultado das forças aliança - conjuntas.

Deriva da independência norte-americana, sem dúvidas, a maior e melhor exposição sobre o federalismo, mormente a partir de artigos publicados por três expoentes políticos norte-americanos: Alexander Hamilton, James Madison e John Jay. Com a independência dos Estados Unidos em 1776, no entanto, manteve-se um regime de confederação (pacto confederativo), segundo o qual os Estados se uniam para a finalidade de garantia da independência, mas mantendo cada um sua soberania'.

Em 1787, com a Convenção da Filadélfia - que aprovou a Constituição dos Estados Unidos -, os Estados são convidados a repensar o arranjo federativo, mormente no tocante ao enfraquecimento dos entes se mantido o regime utilizado. Nos artigos federalistas, Jay, Madison e Hamilton apresentam as vantagens da criação da União, abdicando os Estados de sua soberania, embora preservando sua autonomia, e criticando os posicionamentos antifederativos ${ }^{2}$.

\footnotetext{
1 "As treze colônias inglesas, ao se liberarem da dominação inglesa, constituíram Estados soberanos (ordens jurídicas independentes) que firmaram um tratado internacional criando a Confederação. Posteriormente, em face das dificuldades para a execução daquele tratado internacional, políticos e juristas norte-americanos, como John Jay, Alexander Hamilton e James Madison, pregaram a necessidade do estabelecimento de outro pacto entre os Estados contratantes, de modo que a união entre eles fosse duradoura. Convocou-se uma reunião dos Estados em Filadélfia para a discussão dessa tese e, eventualmente de uma Constituição reunificadora, pois pretendia-se a revisão dos 'Artigos da Confederação' (...) Vencida a resistência de alguns Estados que não pretendiam abdicar de sua soberania, foi editada a Constituição, a qual previu que 'os poderes legislativos pela presente Constituição serão atribuídos ao Congresso dos EUA, composto do Senado e da Câmara dos Representantes' (art. I, seção I)" (TEMER, 1998, p.71-72).

2 "As garantias adicionais à preservação do governo republicano, da liberdade e da prosperidade, resultante da adoção do projeto ora em discussão, consiste principalmente nas restrições que a preservação da União deverá impor às facções e insurreições locais e às ambições dos indivíduos poderosos em cada um dos Estados, que tentarão reunir suficiente crédito e influência, conquistando líderes e adeptos, para se tornarem déspotas do povo; na redução das oportunidades de problemas com estrangeiros que a dissolução da Confederação provocará e facilitará; na prevenção de aumento de efetivos militares, que poderão dar margem a conflitos entre os Estados, em caso de desunião; na
} 
Reinou, por fim, um meio-termo, entre o desenho de Thomas Jefferson, que defendia grande autonomia política aos Estados-membros e as posições federalistas, defensoras de uma União forte e centralizadora. Esse meio-termo, e o direcionamento dos Estados autônomos e soberanos para uma Federação, formada pela União de todos, apresenta o federalismo norte-americano como centrípeto, isto é, em direção ao centro. Assim, historicamente, os Estados Unidos assistiram uma gama de Estados soberanos abdicando mão de sua independência em prol do todo formado pela União. Daí seu preâmbulo:

Nós, o Povo dos Estados Unidos, a fim de formarmos uma União mais perfeita, estabelecer a Justiça, assegurar a tranquilidade interna, prover a defesa comum, promover o bem-estar geral, e garantir para nós e para os nossos descendentes os benefícios da Liberdade, promulgamos e estabelecemos esta Constituição para os Estados Unidos da América.

E justamente por essa posição mediana que restou vencedora, a marca do federalismo norte-americano é uma tendência à federação sem abandono das forças locais, isto é, preservando parcela da força política dos Estados. Daí porque os Estados preservaram um enorme leque de competências e capacidade tributária. Diferentemente do federalismo brasileiro, nos Estados Unidos, os membros é que legislam, por exemplo, sobre direito civil e penal.

A propósito, ressaltam os federalistas (HAMILTON; MADISON; JAY, 1984, p.383):

Os poderes delegados ao governo federal pela Constituição proposta são poucos e definidos; os que permanecem com os governos estaduais são numerosos e imprecisos. Aqueles serão exercidos principalmente sobre tópicos externos, tais como guerra, paz, negociações e comércio exterior, com o qual o poder de taxação estará mais intimamente ligado. Os poderes reservados aos Estados se estenderão sobre todos os tópicos que, no curso normal da vida do país, dizem respeito às liberdades e bens do povo, à ordem interna e aos aperfeiçoamentos e progresso do Estado.

expressa garantia de uma forma de governo republicano em cada um deles; na absoluta e total exclusão de títulos de nobreza; e nas precauções contra a repetição daquelas práticas, em alguns governos estaduais, que minaram as bases da prosperidade e do crédito, plantaram a desconfiança mútua entre todas as classes de cidadãos e provocaram um desalento quase total no ânimo do povo". (HAMILTON; MADISON; JAY, 1984, p.634). 
Diferentemente, o Brasil, desde a Proclamação da República, em 1889, ergueu-se sob a sombra de um poder central extremamente centralizador, vivenciando inúmeros retrocessos centralizadores, intercalados por nuances descentralizadoras. Assim, para se ter ideia, no início do Estado Novo de Vargas, uma cerimônia marcou o incêndio das bandeiras estaduais, como forma de demonstrar a unificação em torno de um ente central e forte. Posteriormente, 21 anos de regime militar serviram para ampliar o poderio da União (TEMER, 1998, p.73-74).

Dessa forma, com o poder nascendo na União e apenas posteriormente e por liberalidade desta sendo transferido a outros entes, o federalismo brasileiro marcouse por ser centrífugo, isto é, fugindo-se do centro, mas sem olvidá-lo de forma peremptória. Assim:

O modo como se repartem as competências indica que tipo de federalismo é adotado em cada país. A concentração de competências no ente central aponta para um modelo centralizador (também chamado centrípeto); uma opção pela distribuição mais ampla de poderes em favor dos Estadosmembros configura um modelo descentralizador (ou centrífugo). Havendo uma dosagem contrabalanceada de competências, fala-se em federalismo de equilíbrio (MENDES; COELHO E BRANCO, 2003, p.801).

E não seria pelas mãos da Constituição de 1988 que tal delineamento histórico se faria diferente, embora com o esforço de diminuir o poder central em prol dos poderes estaduais e municipais. Daí a razão de a União ainda conservar grande parte da competência legislativa e da captação de recursos financeiros, tendência que, a nosso ver, arranha em grande parte o sistema federalista pátrio.

Independentemente da construção histórica do federalismo, no entanto, algumas características dele decorrem, consoante ensina Moraes (2008, p.287): a) os cidadãos dos Estados-membros passam a possuir uma única nacionalidade, a nacionalidade da Federação; b) as competências são distribuídas entre os entes federativos; c) necessidade de que cada ente possua competência tributária que the garanta renda para seu sustento; d) poder de auto-organização dos entes federados; e) restrição taxativa à possibilidade de intervenção federal; f) participação dos Estados no Legislativo Federal, de forma a concorrer para a formação da vontade da União; g) possibilidade de modificação dos Estados, a depender da população afetada; h) necessidade de órgão Supremo do Judiciário para proteção da Constituição Federal. 
Além disso, com o pacto federativo, e a criação da União, não surge direito de arrependimento da parte, tornando-se o vínculo indissolúvel (art. 1ํ, caput). Com a criação da Federação, os Estados abandonam sua própria soberania em prol da União, a qual, deixando de existir, impede que tais Estados possam novamente se declarar soberanos e, assim, desligarem-se da União. Melhor dizendo, como os Estados deixam de ser soberanos, eles não possuem mais autonomia suficiente para se desvincularem do todo. Sua autonomia (art. 18), passa a se desenhar nos estritos termos constitucionais. Quem ingressa na Federação, abdica, tecnicamente, do seu direito de secessão. Diz-se tecnicamente porque é salutar lembrar que em atos revolucionários, o membro pode se insurgir e obter, com apoio de sua população, a separação do ente total.

Ademais, a República Federativa do Brasil, sendo união indissolúvel, reprime não apenas a secessão, como também qualquer emenda que tende a abolir a própria Federação, como, por exemplo, modificando o próprio artigo 1ํㅡㄹ. caput. Assim, nos termos do artigo $60, \S 4^{\circ}$, I, CF, não será objeto de deliberação a proposta de emenda tendente a abolir a forma federativa de Estado.

A despeito das duas observações acima, aliás, salutar o magistério de Cunha Junior (2013, p.858-859):

\begin{abstract}
A quarta característica da Federação é a sua indissolubilidade. O pacto federativo é indissolúvel, não se admitindo invocação do chamado direito de secessão, este previsto exclusivamente nas confederações. Tão importante é essa característica que há severas sanções contra atos que a contrariem, como é o caso da medida da intervenção federal nos Estados-membros. A intervenção constitui, sem dúvida, um dos meios mais eficientes e expeditos para a mantença do federalismo. A quinta característica é a existência de uma Constituição escrita e rígida que contenha um núcleo imutável que proteja o próprio pacto federativo. Ora, como foi visto linhas atrás, a repartição de competência, como mecanismo de descentralização política, corresponde a um processo engendrado diretamente pela própria Constituição. Contudo, não basta a só existência de uma Constituição. Exige-se mais: é necessário que essa Constituição seja rígida e que torne o pacto federativo insuscetível de supressão, sob pena de restar frustrada a própria organização federal que o texto constitucional fundamentou.
\end{abstract}

Com a criação da União, no federalismo centrípeto, surge um novo Estado em substituição aos Estados soberanos dantes havidos. Daí a razão dos habitantes da totalidade serem havidos agora como nacionais de um único Estado, ainda que antes 
fossem nacionais de cada um dos Estados-membros. Isso não ocorre no federalismo centrífugo, pois os habitantes já o eram nacionais do mesmo Estado.

Ainda, com a Federação, a regulação dos Estados-membros é feita pela Constituição, que estabelece a gama de autonomia e o núcleo de competência de cada ente. No caso do federalismo centrípeto, como o norte-americano, cujos Estados soberanos se uniam por meio de uma Confederação, a Constituição substitui um Tratado Internacional antes reinante, instrumento apto a regular relações entre Estados soberanos internacionais.

\section{FEDERALISMO FISCAL BRASILEIRO: UMA ANÁLISE HISTÓRICA DA PARTICIPAÇÃO DOS ENTES FEDERADOS}

Feitas as discussões jurídicas sobre o federalismo, objetiva-se aqui, uma retrospectiva do federalismo brasileiro e a participação dos entes federados. Nesta questão, de acordo com Fiori há grande dificuldade na formulação de uma definição única do federalismo, havendo duas vertentes nas definições do termo; na primeira vertente o essencial é a preservação simultânea, sem a existência de incompatibilidade, dos interesses dos povos das diferentes regiões; na segunda encontram-se autores preocupados com a questão do poder, que difere de momento para momento, de cada ente da federação, nessa definição do poder e participação de cada esfera as competências tributárias e serviços a serem prestados pelas unidades federativas são de grande importância no debate (FIORI, 1995).

Este trabalho concentra-se mais nessa segunda linha de autores que identifica o sistema tributário como um elemento da divisão de poder e participação das diferentes esferas da federação. É o resultado dessa divisão que caracteriza cada sistema federativo no momento, dado que se encontra em constante mutação devido à disputa que muitas vezes as esferas de governo realizam por aumento na participação tributária, o que pode implicar em tensões dentro do federalismo na disputa por receitas e espaço na gestão.

De qualquer forma, para a maior parte dos autores, há concordância quanto à característica que o federalismo possui em manter a existência concomitante de 
autonomias do Governo Central e das esferas subnacionais, havendo assim a conservação da soberania de todas as esferas convivendo dentro de uma mesma federação (FIORI, 1995).

O Federalismo brasileiro apresenta-se de forma a prever cooperação entre os entes federados, União, Estados, Distrito Federal e Municípios. Entretanto se faz fundamental a discussão dos diversos momentos vividos pelo país, seja na questão da autonomia de cada ente, seja na condução pela União da política e dos rumos do desenvolvimento, neste sentido, o sistema tributário constitui um importante elemento.

Assim, o federalismo, além da questão jurídica, histórica e política apresenta um componente econômico. "No caso brasileiro, o equilíbrio federativo é particularmente tensionado pela necessidade do enfrentamento das desigualdades sociais e regionais, historicamente profundas e persistentes" (MENDES, 2013, p.55).

Para Rezende há um caráter municipalista do federalismo brasileiro e também aponta para as fortes diferenças regionais (REZENDE, 1995). Ainda de acordo com Mendes (2013), até os dias atuais, o Brasil carece de um pacto entre os entes federativos que conduzam o país ao desenvolvimento.

Apesar do federalismo não se reduzir à questão tributária, a análise contemplada neste trabalho é a da distribuição vertical (mesmo considerando-se a análise da distribuição horizontal ${ }^{3}$ tão importante quanto, dadas as diferenças regionais), dos recursos por uma perspectiva histórica no Brasil.

Foi a Constituição Federal de 1891 que estabeleceu o federalismo no Brasil, no modelo que Rui Barbosa copiou dos Estados Unidos. Como até nos anos 30 do século XX a economia brasileira apresentava um padrão primário-exportador, o sistema tributário concentrava-se na tributação da importação, chegando este tributo a apresentar $40 \%$ da receita tributária total do país (IBGE, 2003).

É justamente quando o sistema primário-exportador baseado no complexo cafeeiro entra em crise (anos 30 do século XX), dando lugar a um sistema em que a dinâmica passa a ser a industrialização, que se percebe a necessidade de se repensar a estrutura tributária.

\footnotetext{
${ }^{3}$ Por distribuição vertical entende-se a repartição entre União, Estados, Distrito Federal e Municípios, enquanto a distribuição horizontal discute a distribuição entre o grupo de Estados e grupo de Municípios.
} 
Assim, a Constituição de 1934 passa a conter a preocupação de garantir que o sistema tributário vá ao encontro das novas funções do Estado e das novas condições da economia. Oliveira (1991, p.24) observa que ocorre:

\begin{abstract}
A instituição do imposto sobre vendas e consignações (IVC), ampliando o campo da incidência do antigo imposto sobre vendas mercantis de 1923, a ampliação da área de incidência para outros produtos do imposto do consumo, e a maior abrangência do imposto sobre a renda, emergiam como medidas mais consentâneas à nova realidade da economia, então calcada, basicamente, na atividade interna. Assim, a ampliação e generalização do imposto sobre a produção e circulação de mercadorias e do imposto sobre a renda, ao lado do estabelecimento de um teto ao imposto de exportação, apresentavam-se como a principal tentativa ensaiada para coadunar os instrumentos de política econômica à nova realidade. Com a criação de tributos de competência dos municípios, pode-se dizer que foi com esta constituição que o sistema tributário do país, pela primeira vez, delimitou expressamente o campo de competência de tributos para a esfera federal, estadual e municipal.
\end{abstract}

$\mathrm{Na}$ constituição de 1934 foi criado o IVC - Imposto sobre Vendas e Consignações - ampliando o imposto sobre vendas mercantis de 1922. Também se promoveu uma generalização do imposto de renda, aumentando seu campo de incidência. Essas medidas visavam compatibilizar os recursos tributários com a participação cada vez maior do Estado na economia.

Foi na constituição de 1934 que pela primeira vez delimitaram-se as competências do governo nacional, governos estaduais e governos municipais. Mas foi na Constituição de 1937 que houve um aumento da participação dos impostos internos. Assim o imposto sobre importação que até os anos 30 era a principal fonte de recursos tributários perde participação, o que mostra a própria transformação pela qual o país passava, aumentando a participação dos impostos sobre produtos industrializados e imposto sobre a renda e proventos.

O imposto de importação que havia sido o principal tributo cai para $4,04 \% \mathrm{em}$ 1955 , em contrapartida, o aumento do imposto de renda e proventos aumenta de $6,15 \%$ em 1935 para $34,58 \%$ em 1955 e do imposto sobre consumo de $21,6 \%$ em 1935 para $31,31 \%$ em 1955 (IBGE, 2003).

Em 1946 com a elaboração de uma nova constituição houve algumas alterações no sistema tributário, mas as principais características foram preservadas. 
No decorrer dos anos 40 e, principalmente nos anos 50, o Estado assume cada vez mais atividades, esse aumento de atividades é consolidado no Plano de Metas, no qual o Estado propõe-se a combater os "pontos de estrangulamento" da economia, e para isso necessita de recursos.

São os problemas encontrados no financiamento inflacionário do Plano de Metas, levando a uma desaceleração do crescimento nos anos 60 , que irá culminar na realização de uma reforma tributária.

Ao se realizar esta análise, verifica-se que a reforma tributária de 1966/1967 centralizou tributos e decisões de investimento no governo central de maneira a atender os objetivos do governo no momento, que eram principalmente de condução da atividade econômica e formação de capital.

A reforma tributária de 1988 , por sua vez, caracterizou uma nova fase configurada por um sistema tributário que permitia maior participação e autonomia de Estados, Distrito Federal e Municípios. Importante destacar que este processo não foi repentino e sim gradual. Conforme o poder central perdia ou cedia espaço no comando da política nacional, Estados e Municípios aumentavam sua participação nas decisões e também na receita tributária. O poder político e o poder tributário estiveram juntos nas mudanças ocorridas.

Não menos importante ressaltar que, nos últimos anos, a União tem aumentado sua participação com a criação de contribuições e a Desvinculação das Receitas da União - DRUs.

A reforma tributária de 1966 foi resultado de um Estado centralizado e de um regime de ditadura exercido pelo governo. Assim, o sistema tributário funcionava como um elemento de centralização de poder. A Reforma de 1966 é coerente com um governo que precisava de fundos, pois passava a ser o condutor da economia.

A concentração na União da maior parte dos tributos surgiu como um elemento fundamental para o fortalecimento do Estado e acúmulo de capital. Houve assim o "desmoronamento do moribundo federalismo fiscal e o aprofundamento da dependência dos estados e dos municípios do poder central" (OLIVEIRA, 1991, p.50).

A estrutura tributária instalada pela reforma de 1966, visando a centralização da condução da economia na esfera da União, reduziu a autonomia política, financeira 
e tributária dos Estados e Municípios retirando desses o direito de cobrança de uma série de tributos.

Para compensar estas perdas foi criado um sistema de transferências que eram vinculadas a determinadas categorias e programas de gastos, não se permitindo sua livre aplicação. Entre essas transferências estão o FPM (Fundo de Participação dos Municípios), FPE (Fundo de Participação dos Estados) e a QP-ICM (Quota parte do Imposto sobre Circulação de Mercadorias).

Com o passar dos anos, após a reforma de 1966, foram ocorrendo modificações no que se refere ao sistema tributário. Serra observa que no final da década de 70 e início da de 80, com o agravamento da crise econômica e da situação financeira do setor público, principalmente Estados e Municípios, junto com a abertura do sistema político, na qual as eleições de 1982 (Governadores) e 1985 (Prefeitos das Capitais) foram importantes peças, exerce-se uma grande pressão para mudanças no sistema tributário no sentido de aumentar as receitas dos estados e municípios e estabelecer um federalismo fiscal no Brasil (SERRA, 1991).

Se a centralização tributária era um elemento fundamental para a condução de uma política econômica concentrada no âmbito da União, é justamente quando a União começa a perder seu caráter de condutora absoluta dos rumos políticos e econômicos do país, e inicia-se uma abertura política, que ocorrem modificações no sistema tributário, embora insuficientes, como apontamos. É importante notar essa relação, uma vez que o sistema tributário representa um importante elemento de poder político.

Dentro desse processo foram tomadas várias medidas no sentido de descentralização dos recursos, sobretudo no que se refere ao Fundo de Participação dos Municípios - FPM e Fundo de Participação dos Estados - FPE. Verificaram-se constantes elevações nos percentuais do Imposto sobre Produtos Industrializados IPI e Imposto de Renda - IR, que compõem estes fundos.

Nos anos 80 , ocorrem as eliminações de transferências vinculadas, mas mantiveram-se as transferências negociadas, isto é, sem a obrigatoriedade de critérios econômicos e sociais, e sim, muitas vezes, políticos. 
Em 1983, a emenda "Passos Porto", também chamada de minirreforma tributária, aumentou a participação dos Estados, Distrito Federal e Municípios nas receitas da União.

As mudanças mais importantes foram as elevações do FPM e do FPE. A emenda Calmon, estabeleceu o aumento do percentual do orçamento dos Estados, Municípios e Distrito Federal vinculado à educação (de 13\% para $25 \%$ ). Havendo assim, o fortalecimento de Estados e Municípios e uma rediscussão do federalismo no Brasil que se consubstanciaram na Constituição de 1988.

Já a Reforma tributária de 1988 caracterizou-se por um aumento da participação dos Municípios nas receitas disponíveis.

Com a Constituição de 1988, um novo sistema tributário foi implantado, alterando não só a competência, mas também os percentuais de transferências. Entre as principais mudanças verificou-se o aumento do percentual federal (IR e IPI) destinado aos municípios, que passara de $17,5 \%$ para $22,5 \%$ e a criação de partilha de $10 \%$ do IPI com os estados exportadores de produtos industrializados. O ITBI Imposto de Transmissão de Bens Imóveis "inter vivos" e "causa mortis", antes pertencente aos Estados, foi desmembrado, ficando o "inter vivos" a cargo do município.

A arrecadação de Imposto sobre Operações Financeiras - IOF sobre ouro passou a ser partilhada em $70 \%$ com os Municípios onde foram feitas as extrações. Proibiu-se a União de isentar impostos de abrangência estadual e municipal (isenção heterônoma). O ICM foi transformado em ICMS, incorporando os impostos, antes de competência federal, sobre combustíveis e lubrificantes, energia elétrica e mineração, serviços de transporte e comunicação, aumentando a transferência para os Municípios de $20 \%$ para $25 \%$.

Assim, observa-se o aumento da autonomia pretendida pelos Municípios: Os Municípios que em 1960 tinham uma participação na receita disponível de 6,5\% do PIB em 1960 passaram a ter 16,9\% em 1992, os Estados tiveram uma redução de 34\% do total da receita disponível em 1960 para 31\% em 1992 e a União uma redução de $59,4 \%$ para $52,2 \%$ no mesmo período (AFONSO, 1992). 
Este cenário relatado pode ser observado por meio do Quadro 1, no qual se verifica a mudança dos tipos de impostos bem como a competência de cada ente federado.

Quadro 1: Competência Tributária - Brasil - 1891/1988

\begin{tabular}{|c|c|c|c|c|c|c|c|}
\hline Competência tributária nas Constituições & $\begin{array}{c}189 \\
1\end{array}$ & $\begin{array}{c}193 \\
4\end{array}$ & $\begin{array}{c}193 \\
7\end{array}$ & $\begin{array}{c}194 \\
6\end{array}$ & $\begin{array}{c}196 \\
7\end{array}$ & $\begin{array}{c}196 \\
9\end{array}$ & $\begin{array}{c}198 \\
8\end{array}$ \\
\hline \multicolumn{8}{|l|}{ Da União } \\
\hline Imposto sobre importação & $\mathbf{X}$ & $\mathbf{X}$ & $\mathbf{X}$ & $\mathbf{X}$ & $\mathbf{X}$ & $\mathbf{X}$ & $\mathbf{X}$ \\
\hline Imposto sobre exportação & - & - & - & - & $X$ & $X$ & $X$ \\
\hline Direito de entrada, saída e estadia de navios & $\bar{X}$ & - & - & - & - & - & - \\
\hline Taxa de correios e telégrafos federais & $\mathrm{X}$ & - & - & - & - & - & - \\
\hline $\begin{array}{l}\text { Taxas telegráficas, postais e de outrso serviços } \\
\text { federais, de entrada, saída e estadia de navios e } \\
\text { aeronaves }\end{array}$ & - & $\mathrm{X}$ & $\mathrm{X}$ & - & - & - & - \\
\hline Imposto de consumo, exceto combustíveis & - & $\mathrm{X}$ & - & - & - & - & - \\
\hline Imposto de consumo de quaisquer mercadorias & - & - & $\mathrm{X}$ & $\mathrm{X}$ & - & - & - \\
\hline $\begin{array}{l}\text { Imposto de renda, exceto sobre renda cedular de } \\
\text { imóveis }\end{array}$ & - & $\mathrm{X}$ & - & - & - & - & - \\
\hline Imposto de renda & - & - & $\mathrm{X}$ & $\mathrm{X}$ & $\mathrm{X}$ & $\mathrm{X}$ & $\mathrm{X}$ \\
\hline $\begin{array}{l}\text { Imposto sobre transferência de fundos para o } \\
\text { exterior }\end{array}$ & - & $\mathrm{X}$ & $\mathrm{X}$ & $\mathrm{X}$ & - & - & - \\
\hline Imposto sobre atos emanados do seu governo & - & $\mathrm{X}$ & $\mathrm{X}$ & $\mathrm{X}$ & - & - & - \\
\hline Impostos nos territórios & - & $\mathrm{X}$ & $\mathrm{X}$ & $\mathrm{X}$ & $\mathrm{X}$ & $\mathrm{X}$ & - \\
\hline Taxas de selo & $\mathrm{X}$ & - & - & - & - & - & - \\
\hline $\begin{array}{l}\text { Imposto único sobre lubrificantes e combustíveis, } \\
\text { minerais e energia elétrica }\end{array}$ & - & - & - & $\mathrm{X}$ & $\mathrm{X}$ & $\mathrm{X}$ & - \\
\hline Contribuição de melhoria & - & - & - & $\mathrm{X}$ & $\mathrm{X}$ & $\mathrm{X}$ & $\mathrm{X}$ \\
\hline Taxas & - & - & - & $\mathrm{X}$ & $\mathrm{X}$ & $X$ & $\mathrm{X}$ \\
\hline Imposto sobre propriedade territorial rural & - & - & - & - & $\mathrm{X}$ & $\mathrm{X}$ & $\mathrm{X}$ \\
\hline Imposto sobre produtos industrializados & - & - & - & - & $\mathrm{X}$ & $\mathrm{X}$ & $\mathrm{X}$ \\
\hline $\begin{array}{l}\text { Imposto sobre operações de crédito, câmbio e } \\
\text { seguro }\end{array}$ & - & - & - & - & $\mathrm{X}$ & $\mathrm{X}$ & $\mathrm{X}$ \\
\hline $\begin{array}{l}\text { Imposto sobre serviços de transporte e } \\
\text { comunicações }\end{array}$ & - & - & - & - & $\mathrm{X}$ & $X$ & - \\
\hline Impostos extraordinários (guerra, etc) & - & - & - & $\mathrm{X}$ & $\mathrm{X}$ & $\mathrm{X}$ & $\mathrm{X}$ \\
\hline Empréstimo compulsório & - & - & - & $\mathrm{X}$ & $\mathrm{X}$ & $\mathrm{X}$ & $\mathrm{X}$ \\
\hline Outras fontes de receita (residual) & $\mathrm{X}$ & $\bar{X}$ & $\bar{X}$ & $\mathrm{X}$ & $\mathrm{X}$ & $\mathrm{X}$ & $\mathrm{X}$ \\
\hline \multicolumn{8}{|l|}{ Dos Estados } \\
\hline Imposto sobre exportação & $\mathrm{X}$ & $\mathrm{X}$ & $\mathrm{X}$ & $X$ & - & - & - \\
\hline Imposto sobre imóveis rurais e urbanos & $\mathrm{X}$ & - & - & - & - & - & - \\
\hline
\end{tabular}




\begin{tabular}{|c|c|c|c|c|c|c|c|}
\hline Imposto sobre transmissão de propriedade & $\mathrm{X}$ & - & - & - & - & - & - \\
\hline Imposto sobre indústrias e profissões & $\mathrm{X}$ & $\mathrm{X}$ & $\mathrm{X}$ & - & - & - & - \\
\hline Imposto sobre atos emanados do governo & $\mathrm{X}$ & $\mathrm{X}$ & $\mathrm{X}$ & $\mathrm{X}$ & - & - & - \\
\hline Contribuição sobre correios e telégrafos estaduais & $\mathrm{X}$ & - & - & - & - & - & - \\
\hline $\begin{array}{l}\text { Imposto sobre propriedade territorial, exceto } \\
\text { urbana }\end{array}$ & - & $\mathrm{X}$ & $\mathrm{X}$ & $\mathrm{X}$ & - & - & - \\
\hline $\begin{array}{l}\text { Imposto sobre propriedade de veículos } \\
\text { automotores }\end{array}$ & - & - & - & - & - & - & $\mathrm{X}$ \\
\hline \multirow[t]{2}{*}{ Competência tributária nas Constituições } & 189 & 193 & 193 & 194 & 196 & 196 & 198 \\
\hline & 1 & 4 & 7 & 6 & 7 & 9 & 8 \\
\hline $\begin{array}{l}\text { Imposto sobre transmissão de propriedade causa } \\
\text { mortis }\end{array}$ & - & $\mathrm{X}$ & $\mathrm{X}$ & $\mathrm{X}$ & $\mathrm{X}$ & $\mathrm{X}$ & $\mathrm{X}$ \\
\hline $\begin{array}{l}\text { Imposto sobre transmissão de propriedade } \\
\text { imobiliária inter vivos }\end{array}$ & - & $\mathrm{X}$ & $\mathrm{X}$ & $\mathrm{X}$ & $\mathrm{X}$ & $\mathrm{X}$ & - \\
\hline \multicolumn{8}{|l|}{ Dos Estados - Continuação } \\
\hline $\begin{array}{l}\text { Imposto sobre consumo de combustíveis de motor } \\
\text { de explosão }\end{array}$ & - & $\mathrm{X}$ & - & - & - & - & - \\
\hline Imposto sobre vendas e consignações & - & $\mathrm{X}$ & $\mathrm{X}$ & $\mathrm{X}$ & - & - & - \\
\hline Imposto sobre circulação de mercadorias & - & - & - & - & - & $\mathrm{X}$ & $\mathrm{X}$ \\
\hline Taxa de serviços estaduais & - & $\mathrm{X}$ & $\mathrm{X}$ & $\mathrm{X}$ & $\mathrm{X}$ & $\mathrm{X}$ & $\mathrm{X}$ \\
\hline Contribuição de melhoria & - & - & - & $\mathrm{X}$ & $\mathrm{X}$ & $\mathrm{X}$ & $\mathrm{X}$ \\
\hline Outras formas de receita (residual) & - & $\mathrm{X}$ & $\mathrm{X}$ & - & - & $\mathrm{X}$ & $\mathrm{X}$ \\
\hline \multicolumn{8}{|l|}{ Dos Municípios } \\
\hline Imposto de licença & - & $\mathrm{X}$ & $\mathrm{X}$ & - & - & - & - \\
\hline Imposto predial e territorial urbano & - & $\mathrm{X}$ & $\mathrm{X}$ & $\mathrm{X}$ & - & $\mathrm{X}$ & $\mathrm{X}$ \\
\hline Imposto sobre diversões públicas & - & $\mathrm{X}$ & $\mathrm{X}$ & $\mathrm{X}$ & - & - & - \\
\hline Imposto cedular sobre a renda de imóveis rurais & - & $\mathrm{X}$ & - & - & - & - & - \\
\hline Imposto sobre indústrias e profissões & - & - & - & $\mathrm{X}$ & - & - & - \\
\hline Impostos sobre atos de sua economia & - & - & - & $\mathrm{X}$ & - & - & - \\
\hline Impostos sobre serviços de qualquer natureza & - & - & - & - & $\mathrm{X}$ & $\mathrm{X}$ & $\mathrm{X}$ \\
\hline Imposto sobre transmissão inter vivos & - & - & - & - & - & - & $\mathrm{X}$ \\
\hline Taxas sobre serviços municipais & - & $\mathrm{X}$ & $\mathrm{X}$ & $\mathrm{X}$ & $\mathrm{X}$ & $\mathrm{X}$ & $\mathrm{X}$ \\
\hline Contribuição de melhoria & - & - & - & $\mathrm{X}$ & $\mathrm{X}$ & $\mathrm{X}$ & $\mathrm{X}$ \\
\hline Outras formas de receita (residual) & - & - & - & $\mathrm{X}$ & $\mathrm{X}$ & $\mathrm{X}$ & $\mathrm{X}$ \\
\hline
\end{tabular}

Fonte: IBGE,2003.

Verifica-se no quadro a mudança dos tributos em função do desenvolvimento econômico e industrialização no Brasil, também pode ser observado que Estados e, principalmente Municípios tiveram um aumento na competência tributária. 
A descentralização esteve diretamente associada à lógica do processo de transição democrática "(...) no Brasil, a descentralização foi constitucionalizada e implicou a autonomia ampliada dos estados e a elevação de municípios e do Distrito Federal à condição de entes federados" (LASSANCE, 2012, p.27). Tudo isso, no entanto, não fora suficiente para que gerar nos demais entes federativos o mesmo tipo de autonomia destinada à União. Não bastasse, a União pretendia recuperar a parcela perdida nos últimos anos.

Foi neste sentido que ainda nos anos 90, mas principalmente nos anos 2000, ao implantar uma série de programas sociais e aumento de gastos o governo federal passou a atuar no sentido de tentar recuperar sua participação no total das receitas disponíveis.

Assim, a criação de contribuições que não são transferidas aos Estados e Municípios tem sido uma constante a partir da Constituição de 1988. Além da Contribuição Provisória sobre Movimentação Financeira - CPMF, destaca-se a criação da Contribuição de Intervenção de Domínio Econômico - CIDE em 2001. Em 2005, a participação de cada ente federado nas contribuições existentes apresentava-se da seguinte forma: 94,22\% para a União, 4,64\% Estados e 1,14\% para Municípios, sendo que as contribuições representavam $35,91 \%$ da receita tributária brasileira. Nesta mesma análise, verifica-se que, do total da arrecadação da União, 58,52\% são de contribuições (IBAM, 2005).

Foi com este objetivo também que a Desvinculação das Receitas da União DRU foi criada como Fundo Social de Emergência em 1994, transformado em Fundo de Estabilização Fiscal até dezembro de 1999 e, a partir de 2000, transformado na DRU, e que ainda está em vigor, pois, após várias prorrogações, em agosto de 2016 foi aprovada, após votação na Câmara e no Senado, por Proposta de Emenda Constitucional - PEC, sua vigência até 2023.

A DRU permitia ao governo federal usar $20 \%$ de todos os tributos federais vinculados por lei a fundos ou despesas de forma livre. A principal fonte de recursos da DRU são as contribuições sociais, que respondem a cerca de $90 \%$ do montante desvinculado. A PEC aprovada retroagiu a $1^{\circ}$ de janeiro de 2016 e aumentou 0 percentual para 30\%, conforme artigo 76 do ADCT (SENADO FEDERAL, 2016). Além disso, o artigo 76-A do ADCT criou a Desvinculação de Receitas para Estados e 
Distrito Federal, ao passo que o artigo 76-B a criou aos Municípios, exceto pelas receitas destinadas à saúde e educação, todos com redação dada pela Emenda Constitucional 93/2016.

A Desvinculação é um instituto, no mínimo, polêmico. De um lado, seus defensores entendem que a DRU confere maior maleabilidade ao orçamento, aumentando os recursos livres para utilização em projetos governamentais prioritários e para constituição de poupança necessária para a redução da dívida pública. De outro, os críticos entendem que a finalidade é desviar os recursos da CIDE que deveriam se destinar a interesses públicos para o pagamento de credores da dívida pública. Além disso, implica na retirada de $20 \%$ das contribuições sociais, o que conduzirá ao aumento da carga tributária para suprir essa lacuna (LOPES FILHO, 2007).

Conforme ensina Oliveira (2008, p.358), ainda sob a redação anterior, que desvinculava $20 \%$ das receitas:

\begin{abstract}
Tal dispositivo, praticamente, desvinculou as receitas nele mencionadas das finalidades para que estavam originariamente previstas. Evidente está que o Poder Legislativo abriu mão de dar a palavra final sobre a destinação dos gastos públicos, restringindo sua competência $80 \%$ das receitas, relegando ao critério exclusivo do Executivo os restantes $20 \%$. (...) Outorgou-se ao Executivo faculdade totalmente descabida, ficando a seu alvedrio a alocação de recursos, o que é incompatível com o todo constitucional. No entanto, a norma subsiste e desobriga de qualquer vinculação o comportamento do Chefe do Executivo.
\end{abstract}

Claro que, não é razoável deixar o Chefe do Executivo amarrado às previsões orçamentárias, sendo necessária uma pequena margem de discricionariedade para emprego dos recursos públicos. "Não se cogita, no entanto, de liberar o emprego de recursos de forma indiscriminada. Ao contrário, a tendência é o ajustamento parcial e progressivo de certa liberdade ao Chefe do Executivo, que fica obrigado a cumprir o que no orçamento se estabeleceu" (OLIVEIRA, 2008, p.358).

Mas no que diz respeito ao presente estudo, a DRU nada mais é do que uma consequência da retomada arrecadatória da União para o fim de deixar livres as receitas decorrentes de contribuições. Além disso, conforme mencionado, a desvinculação, na medida em que tende a diminuir a arrecadação para fins sociais, implica no aumento da carga tributária federal. 
De uma forma geral, nota-se que, a despeito das tentativas de descentralização típicas da Constituição de 1988, havia ainda uma forte tendência a um falso federalismo fiscal, em razão das receitas provenientes dos tributos federais. Mesmo com alguns esforços em sentido contrário, insuficientes por sinal, depois de um tempo a União resolveu acentuar-se em direção à recuperação de receitas perdidas.

Desta condição fiscal brasileira, resultam problemas gravíssimos ao federalismo. Primeiramente, insta consignar que os demais entes federados se sujeitam aos repasses voluntários da União, o que, politicamente, tem seu preço. $\mathrm{E}$ essa necessidade de efetuar transferências para salvaguardar a vida de Estados e Municípios acaba servindo como elemento estimulante a práticas de corrupção, seja para compensar os próprios repasses, seja em vista do longo caminho percorrido pela receita.

No mais, no afã de se buscar mais recursos, a ausência de fontes próprias estimula a prática de guerra fiscal entre Estados e até mesmo entre Municípios, além das constantes fiscalizatórias extremamente duvidosas e inovadoras que buscam interpretações legais inexistentes para reclamar a si o pagamento de determinados tributos. É o que veremos adiante.

\section{DESCENTRALIZAÇÃO DE SERVIÇOS, QUEDA DE ARRECADAÇÃO E TRANSFERÊNCIAS, GUERRA FISCAL E CORRUPÇÃO}

Além disso, a crise econômica e o falso federalismo fiscal tendem a acentuar caminhos perigosos, seja quanto aos meios de transferências voluntárias, seja quanto às formas de se buscar maior arrecadação para fazer frente às despesas públicas.

Em primeiro lugar, insta consignar algo que nos parece bastante factível: transferências voluntárias tendem a ter preços políticos. Vamos dizer que, de certa forma, rompe-se com o idealismo de atribuir aos políticos federais a mera defesa do interesse público, sem absolutamente nenhuma reserva quanto aos recursos obtidos. É evidente que a "troca" de favores por recursos ou mesmo de percentuais por recurso é estimulada pela necessidade de obtenção de verbas diretamente da União. E, de 
outro lado, cumpre lembrar que os demais entes federativos, mormente os Municípios, podem se situar em situações de miserabilidade que os empurram ao jogo político.

De acordo com Conti (2012):

[...] as transferências voluntárias, mais do que instrumentos de aperfeiçoamento do federalismo fiscal cooperativo, transformaram-se em armas de destruição da autonomia financeira, e consequentemente do federalismo brasileiro, subordinando municípios e estados à vontade da União. Há uma distorção do processo democrático por meio do qual são eleitos os governantes, uma vez que os responsáveis pela gestão dos entes subnacionais se veem compelidos a aceitar as ofertas que lhe são feitas pelos demais entes federados, sob pena de não terem recursos para atenderem as necessidades de sua população. Muitos prefeitos, por consequência, têm de destinar recursos conforme o interesse da União, detentora dos recursos e do poder de entregá-los a quem lhe convier.

Também, deve-se ressaltar que a necessidade de obtenção de receitas também estimula a guerra fiscal entre Estados e entre Municípios, com o intuito de se tornar mais atraente ao investidor. Isso por si só não seria caótico, mas o fato de que a ação temerária de uns, mesmo com os limites administrativos e legais, pode conduzir os demais a uma situação de penúria arrecadatória, decorrente de sua falta de estrutura e de condições em competir. Logo, o equilíbrio que se espera do federalismo se arranha não apenas em relação à União, mas em relação aos próprios entes com as mesmas competências.

Não é só. No intuito de buscar melhores arrecadações, muitas vezes quem sofre é o contribuinte. Alvo das ações fiscalizatórias, este se vê cercado de incoerências e de ausência total de segurança jurídica decorrentes das interpretações divergentes entre os entes federativos e de criações de teses mirabolantes para justificar a cobrança de tributos indevidos. A prática demonstra, por exemplo, as nuances que performam a cobrança de ISS e ICMS. Aliás, quanto ao ISS, a segurança jurídica passo ao largo quando empresa de determinada localidade presta serviços em outra. A boa sorte deve estar ao lado do contribuinte.

Todas essas situações, angustiadas ainda mais por uma crise econômica que coloca em insolvabilidade Estados e Municípios, chamam a atenção para a necessidade de rediscussão do federalismo fiscal brasileiro, absolutamente desequilibrado e incentivador de condutas que atentam contra a própria Constituição e contra o próprio federalismo. 
No que tange a Guerra Fiscal é importante analisar e estudo apresentado por Medeiros Netto (2003, p.5) na Consultoria Legislativa

\begin{abstract}
A guerra fiscal - protagonizada pelos Estados para atrair investimentos, através de ações que procuram conceder vantagens apenas os benefícios fiscais, mas também incentivos financeiros e imobiliários que representam vantagens locacionais aos olhos dos empresários.
\end{abstract}

Dois aspectos nos chamam atenção no referido estudo: a discussão sobre a guerra fiscal, no caso principalmente em função das alíquotas do ICMS, já discutidas em 2003 e estancadas em função da priorização de outros assuntos pela agenda política brasileira; e a clara análise que na guerra fiscal entre os entes federados, no caso citado entre estados, quem ganha é o setor produtivo, quem perde a arrecadação pública, não havendo ganhadores para os entes federados. Muito se discute a renúncia fiscal promovida pela guerra fiscal represente aumento das margens de lucro para o setor produtivo.

Não menos importante, observar que em cenários de crise com queda da arrecadação e consequente queda das transferências, além de um acirramento da guerra fiscal, municípios têm deixado de prestar serviços essenciais à população, dada a queda na receita disponível.

\title{
5 A CRISE ECONÔMICA E A IMPORTÂNCIA DA DISCUSSÃO DO FEDERALISMO
}

A caracterização do cenário de crise e recessão pode ser feita por meio de alguns dados que reforçam a importância da discussão do federalismo brasileiro neste momento, uma vez que com menos arrecadação e receita a tendência é de um maior acirramento nas questões de competência tributária e transferências.

Importante destacar a queda do Produto Interno Bruto - PIB, vivenciado nos anos de 2015 e 2016, a queda do PIB per capita vivenciado já a partir de 2014, mostrando que o aumento da produção já não acompanhava o aumento da população, o aumento da inflação e aumento do desemprego. 
$\mathrm{Na}$ análise econômica considera-se que depois de dois trimestres seguidos com queda de PIB caracteriza-se o cenário de recessão, cenário este que temos mantido desde 2015, ano que o PIB fechou em queda de 3,8\%, no ano de 2016 acumulava uma queda de $4 \%$ nos três primeiros trimestres (IBGE, 2016), o PIB per capita entrara em queda já em 2014 de U\$ $\$ 15.281,61$ do ano anterior para US\$ $15.162,42$ em 2014 e US\$ 14.454,94 no ano de 20154. Os índices de inflação aumentaram, o IGP-M ${ }^{5}$ mostrou uma inflação de 10,54\% em 2015 e 7,17\% em 2017.

Por se tratar de crise recente ainda há um grande debate sobre os fatores que a motivaram, mas já há certa concordância que ocorreu um colapso da política econômica adotada pelo governo que estimulou os gastos das famílias e endividamento e do próprio governo.

Para continuidade da discussão apresenta-se a seguir duas análises importantes para tecermos alguma conclusão. As transferências do Fundo de Participação dos Municípios- FPM e do Fundo de Participação dos Estados - FPE, não demostram queda, conforme se verifica na Tabela 1 que apresenta os dados da Secretaria do Tesouro Nacional - STN (2017), já se descontando os valores de transferência ao Fundo de Manutenção e Desenvolvimento da Educação Básica e de Valorização dos Profissionais da Educação- FUNDEB:

Tabela 1: Transferências de FPM e FPE ao ano em milhões de Reais- (20102016)

\begin{tabular}{l|l|l}
\hline ANO & FPM & FPE \\
\hline 2016 & $79.910,7$ & $69.910,8$ \\
\hline 2015 & $68.399,0$ & $61.105,7$ \\
\hline 2014 & $64.158,0$ & $58.086,0$ \\
\hline 2013 & $58.878,0$ & $53.304,1$ \\
\hline 2012 & $54.746,8$ & $49.564,4$ \\
\hline 2011 & $53.097,3$ & $48.070,1$ \\
\hline 2010 & $43.068,9$ & $39.024,0$ \\
\hline
\end{tabular}

Fonte: STN, 2017.

\footnotetext{
4 Os valores são apresentados em PPC - Paridade de Poder de Compra é o Produto Interno Bruto convertido para dólares constantes de 2005.

5 O IGP-M Índice Geral de Preços - Mercado calculado pela Fundação Getúlio Vargas reflete a evolução dos preços verificados pelo Índice de Preços por Atacado (IPA), Índice de Preços ao Consumidor (IPC-FGV) e Índice Nacional de Preços da Construção Civil (INCC)
} 
Entretanto, quando se verifica a distribuição dos recursos do FPM e FPE de forma regional, no período de 2003 a 2012, conforme dados da Cartilha do FPM da STN (2017b) têm se a seguinte distribuição regional:

Tabela 2: Distribuição do FPE e FPM por região em percentual (2003-2012)

\begin{tabular}{l|l}
\hline Região & Participação \% \\
\hline $\mathrm{N}$ & 8,8 \\
\hline $\mathrm{NE}$ & 35,5 \\
\hline $\mathrm{SE}$ & 31,1 \\
\hline $\mathrm{S}$ & 17,4 \\
\hline $\mathrm{CO}$ & 7,2 \\
\hline
\end{tabular}

Fonte: STN, 2017b.

Importante considerar então, que conforme critérios de distribuição do FPM e FPE que procuram reduzir as desigualdades sociais, sendo que o FPM considera no seu cálculo fator proporcional à população e inversamente proporcional à renda per capita, e que o FPE tem $85 \%$ de suas receitas destinadas às regiões Norte, Nordeste e Centro-Oeste.

Com base nestes dados, podemos considerar que existe uma disputa horizontal e uma vertical pelos recursos, conforme afirmado anteriormente. Consequentemente, sofre o federalismo brasileiro.

É que com a queda da economia, as transferências negociadas aparecem de forma fundamental para Estados e Municípios, uma vez que não houve redução nas transferências de FPM e FPE. E é esse justamente o ponto que mais solapa o nosso sistema, conduzindo ao que já chamamos de falso federalismo fiscal.

\section{CONCLUSÃO}

O Brasil é um país que adota oficialmente o sistema federalista. E o faz em cópia ao modelo norte-americano de 1787, aqui introduzido em 1891, por meio da primeira Constituição Republicana. 
Todavia, a história tão divergente dos Estados Unidos em relação ao Brasil, acabou transformando o modelo em algo atípico e sem expressividade em termos de equilíbrio entre os entes federativos.

Se na história norte-americana a independência das colônias deu lugar à União, tornando aquelas autônomas, no Brasil fora o próprio Estado Unitário que se repartiu. Na prática, isso significa que no primeiro modelo os Estados-Membros abrem mão apenas do necessário para a união, ao passo que no segundo, a União abdica apenas do que the desinteressa para a criação dos demais entes, seja em termos administrativos, legislativos e fiscais.

A tendência dos chamados federalismos centrífugos, como o nosso, é a preservação da maior parte das competências nas mãos da União, algo que, em certa medida, pode jogar por terra o próprio federalismo, existente apenas em aspectos formais.

No Brasil, como se vê, o federalismo acabou manietando os demais entes federativos, em razão da preservação do caixa forte em poder da União, tornando os demais dependentes de suas transferências voluntárias. Melhor dizendo, sem caixa para fazer frente às suas necessidades, Estados e Municípios tornaram-se dependente da União, o que, evidentemente, rompe com a ideia federalista de equilíbrio.

A tendência centralizadora acentuou-se, ainda mais, a partir dos governos getulistas, nos anos 30, e militares, nos anos 60 em diante. E somente em 1988 houve sinais, ainda bastante tímidos, de redistribuição de força financeira aos demais entes como uma necessidade da democracia renascente.

Apesar dos esforços, vimos que a Constituição de 1988 manteve a União como ente forte $e$, apesar das transferências obrigatórias, a manutenção da dependência da vontade federal se manteve para a sobrevida de alguns Estados e dos Municípios brasileiros.

Mesmo assim, em virtude da pequena perda de arrecadação, a União viu nas contribuições uma forma de retomar sua participação no total tributado, aumentando ainda mais a discrepância fiscal existente. Instrumentos como a DRU, ainda, estimularam a necessidade de aumento da carga tributária federal para fazer frente aos gastos sociais. 
O falso federalismo fiscal brasileiro traz consequências gravosas ao próprio Estado. Cumpre ressaltar que a dependência do ente federal torna os demais entes em escravos políticos da União e, pior, estimula a criação de dutos corruptores.

Além disso, no afã de fazer frente às despesas, a falta de receita implementa as guerras fiscais entre Estados e entre Municípios e assedia ainda mais o contribuinte, que resta à mercê de interpretações absurdas e ausência de segurança jurídica para a realização de suas atividades.

É certo que a disputa por receitas e transferências entre os Estados e entre os Municípios não tem levado ao crescimento econômico. No caso específico das renúncias promovidas pela guerra fiscal, na realidade, tem levado a uma abdicação de receita para o setor empresarial.

Com a atual crise econômica no Brasil (queda de 3,6\% no PIB no ano de 2016, de acordo com o IBGE) a arrecadação também cai e as disputas tornam-se mais acirradas, desta forma a discussão do federalismo brasileiro precisará passar não somente pela questão arrecadatória, mas também pela redefinição do papel dos entes federados e do próprio Estado como um todo.

\section{REFERÊNCIAS}

AFONSO, José Roberto Rodrigues. Aspectos conceituais das relações financeiras intergovernamentais. Estudos Econômicos, São Paulo, v.22, n.1, p.5-32, jan./abr., 1992.

ARAÚJO, Luiz Alberto David. Característicos comuns do federalismo. In: BASTOS, Celso Ribeiro (Coord.). Por uma nova Federação. São Paulo: Revista dos Tribunais, 1995. p.39-52.

CONTI, José Maurício. Transferências voluntárias geram desequilíbrio federativo. Disponível em: < http://www.conjur.com.br/2012-ago-28/contas-vistatransferencias-voluntarias-geram-desequilibrio-federativo>. Acesso em: 8 fev. 2017.

CUNHA JÚNIOR, Dirley da. Curso de direito constitucional. 7.ed. Salvador: JusPodivm, 2013.

FIORI, José Luís. Federalismo e reforma tributária. In: AFFONSO, Rui de Brito, BARROS SILVA, Pedro L. A Federação em Perspectiva: ensaios selecionados. São Paulo: FUNDAP, 1995. p.19-38. 
HAMILTON, Alexander; MADISON, James; JAY, John. O federalista. Brasília: UnB, 1984.

IBGE - Instituto Brasileiro de Geografia e Estatística. Estatísticas do século XX. Rio de Janeiro, 2003.

INSTITUTO BRASILEIRO DE ADMINISTRAÇÃO MUNICIPAL - IBAM. Panorama das finanças municipais em 2005. Rio de Janeiro, 2005. (Série Estudos Especiais n. 184). Disponível em: <http://www.ibam.org.br/publique/cgi/cgilua.exe/sys/start.htm>. Acesso em: 20 ago. 2007.

LASSANCE, Antonio. Federalismo no Brasil: Trajetória institucional e alternativas para um novo patamar de construção do Estado. In: IPEA - Instituto de Pesquisa Econômica Aplicada. Federalismo à brasileira: questões para discussão. IPEA, 2012. Disponível em: <http://www.ipea.gov.br/portal/images/stories/PDFs/livros/livros/livro_federalismoabr asileira_v08.pdf>. Acesso em: 17 out. 2016.

LOPES FILHO, Osiris. A prevalência do interesse nacional. Disponível em: <http://www.correiocidadania.com.br/antigo/ed527/osiris.htm>. Acesso em: 5 fev. 2017.

MEDEIROS NETTO, José da Silva. Guerra Fiscal entre os Estados. Brasília, DF: Consultoria Legislativa; Câmara dos Deputados, 2003.

MENDES, Constantino Cronemberg, O Federalismo no Brasil: pesquisas, estudos e reflexões do IPEA. Disponível em: $<$ http://ipea.gov.br/agencia/images/stories/PDFs/boletim_analise_politico/120906_bol etim_analisepolitico_02_cap8>. Acesso em 17 out. de 2016.

MENDES, Gilmar Ferreira; COELHO, Inocêncio Mártires; BRANCO, Paulo Gustavo Gonet. Curso de Direito Constitucional. 3.ed. São Paulo: Saraiva, 2008.

MORAES, Alexandre de. Direito constitucional. 23.ed. São Paulo: Atlas, 2008.

OLIVEIRA, Fabrício Augusto de. Reforma tributária de 1966 e acumulação de capital no Brasil. 2 ed. Belo Horizonte: Oficina de Livros, 1991.

OLIVEIRA, Régis Fernandes. Curso de direito financeiro. 2.ed. São Paulo: Revista dos Tribunais, 2008.

REZENDE. Fernando. Os rumos da reforma fiscal. Revista do Servidor Público, Brasília, v.119, n.1, p. 153-154, jan./abr., 1995.

SENADO FEDERAL. Senado aprova proposta que prorroga a DRU até 2023. Agência 
http://www12.senado.leg.br/noticias/materias/2016/08/24/senado-aprova-propostaque-prorroga-a-dru-ate-2023>. Acesso em: 19 out. 2016.

SERRA, José. Finanças Públicas Municipais: Trajetórias e Mitos, Conjuntura Econômica, Rio de Janeiro: Fundação Getúlio Vargas, out./nov., 1991.

STN - SECRETARIA DO TESOURO NACIONAL. Boletim FPM/FPE/IPIExportação. legais\#boletins> (vários anos). Acesso em: 20 fev. 2017.

. O que você precisa saber sobre as transferências constitucionais e legais-Fundo de Participação dos Municípios - FPM. Disponível em: <http://www.tesouro.fazenda.gov.br/documents/10180/190777/CartilhaFPM.pdf>. Acesso em 20 fev. 2017.

TAVARES, André Ramos. Curso de Direito Constitucional. 11.ed. São Paulo: Saraiva, 2013.

TEMER, Michel. Elementos de direito constitucional. 14.ed. São Paulo: Malheiros, 1998. 